\title{
Introdução à Antropologia (semestre de inverno 1781/82)
}

\author{
Immanuel Kant
}

Tradução de Márcio Suzuki 



\section{Apresentação}

O texto traduzido nas páginas que seguem figura como introdução ao curso de Antropologia que Kant ministrou em Königsberg no semestre de inverno de 1781-1782. Esse curso é o primeiro da chamada fase "crítica", e o mais longo dos publicados por Reinhardt Brandt e Werner Stark nos dois enormes tomos que constituem o volume XXV da edição da Academia (Berlim: de Gruyter, 1997). À diferença dos demais, catalogados pelo nome do aluno, do detentor do manuscrito ou do local em que foi encontrado ou depositado, o curso recebeu dos organizadores o título Menschenkunde (literalmente: "conhecimento do homem"), denominação que lhe fora dada por Fr. Ch. Starke (pseudônimo de Johann Adam Bergk) quando o publicou pela primeira vez em 1831. O texto que a edição da Academia traz da Antropologia de 1781-1782 é bem maior que o da edição Starke ${ }^{1}$, por ter sido estabelecido também a partir de outro manuscrito (sempre da mão de aluno ou copista) encontrado na Biblioteca Nacional de São Petersburgo.

Embora não contenha essa designação, a "Introdução" à Menschenkunde (assim como também em parte a do curso de 1784/1785 intitulado Mrongovius) apresenta uma peculiaridade em relação às outras introduções dos cursos de antropologia e mesmo ao Prefácio à Antropologia de um ponto de vista pragmático, publicada em 1796. É que nela se pode reconhecer melhor o lugar que Kant reserva ao conhecimento do homem no conjunto do seu sistema da filosofia, e com isso também talvez fique mais

1 Do qual há reedição a cargo de Giorgio Tonelli (Hildesheim, Olms, 1976). 
claro o que quer dizer quando afirma, na Lógica, que as três perguntas (“o que posso saber?", “o que devo fazer?", “o que me é lícito esperar?”) remetem à questão “o que é o homem?”.

Responder à pergunta "o que é o homem?" supõe um método diferente da ciência feita nos moldes escolares. Kant afirma que a ciência acadêmica é, em suas próprias palavras, uma "perfeição nada desprezível". Como saber rigoroso, ela é mesmo absolutamente indispensável, mas, mesmo assim, do ponto de vista do homem, um saber bastante insatisfatório. Na divisão das formas de "ensino" ou aprendizado por que tem de passar o ser humano, ela ocupa o primeiro degrau: a ciência que se obtém na academia corresponde a uma "habilidade" é uma habilitação apenas teórica. Para sua efetivação no mundo, é preciso um conhecimento aplicado chamado prudência. Grau intermediário da formação, prudência é a capacidade de saber aplicar os conhecimentos teóricos aos fins estabelecidos por cada um. Essa capacidade pragmática prepara o terreno para o terceiro nível de formação, a sabedoria, que se situa no campo moral. Do ponto de vista do conjunto das faculdades superiores, esses três níveis de aprendizado correspondem grosso modo ao entendimento, ao juízo e à razão (cf. $\$ 59$ da Antropologia); do ponto de vista do sistema crítico, à Primeira, à Terceira e à Segunda Críticas.

A dada altura do texto, Kant dá um exemplo para explicar a passagem do primeiro ao segundo nível da formação: não basta ser um hábil relojoeiro, mas é preciso saber fazer o relógio chegar o mais rápido aos homens. A analogia com as questões metafísicas salta à vista: também os filósofos perderam tempo demais tentando saber como o grande artesão construiu o enorme relógio que é o mundo, esquecendo-se de se perguntar o que podiam fazer com ele. Sem dúvida, era absolutamente necessário enten-

2 Sobre essa remissão à antropologia, veja-se, no texto anterior, o comentário de Pedro Paulo Pimenta às observações de Edgar Wind e Michel Foucault e também a apresentação de Clélia Aparecida Martins à tradução brasileira da Antropologia de um ponto de vista pragmático (São Paulo: Iluminuras, 2006, p. 12). 
der como funcionava o seu mecanismo, mas também é preciso perguntar se é de alguma valia. O filósofo deveria, na verdade, prestar mais atenção a essa mudança de foco, em que se passa da consideração do mecanismo do relógio para a consideração do seu fim. Lendo os seus cursos de antropologia, pode-se constatar quão clara era para Kant a compreensão das mudanças de significação, onde um sentido segundo se acrescenta sem apagar inteiramente o primeiro. O sentido "crítico" (ou "antropológico") não necessariamente exclui o sentido "dogmático" consagrado. ${ }^{3}$ As significações dependem do contexto, e a linguagem, portanto, como a antropologia, é claramente pragmática. Assim, não se deve dizer que os filósofos dogmáticos estavam errados quando deram a uma parte da ontologia o nome "cosmologia" ou "conhecimento do mundo". O problema é que esse sentido da palavra "mundo" já não vale fora do mundo deles, ou seja, no próprio mundo. Aqui, conhecimento do mundo já não quer dizer conhecimento das coisas materiais e suas leis (o relógio considerado em sua mecânica), mas conhecimento dos seres humanos nas suas relações sociais. Aqui, o conhecimento não visa mais os objetos, mas o sujeito ou os sujeitos.

3 Vale a pena remeter aqui o leitor ao trabalho de doutorado Crítica e Autonomia em Kant: a forma legislativa entre determinaçăo e reflexăo, de Maurício Cardoso Keinert (São Paulo: Universidade de São Paulo, 2006). Como bem mostra o primeiro capítulo do trabalho, entender o aspecto positivo do conceito crítico de filosofia não significa simplesmente opô-lo ao conceito dogmático, já que ambos, ao contrário, devem ser pensados a partir da compreensão da relação entre determinação e reflexão. Se para Keinert é preciso rever a posição do filósofo "dogmático" na filosofia crítica, em outra tese de doutorado também recentemente defendida (Oliver Tolle, Luz Estética: a ciência do sensivel de Baumgarten. Entre a arte e a iluminação. São Paulo: Universidade de São Paulo 2007), o leitor poderá conhecer o quanto Kant deve sua concepção geral de filosofia a ninguém menos que o filósofo dogmático Baumgarten. A sugestão da dívida de Kant para com Baumgarten é apenas implícita, pois o interesse todo do trabalho está em mostrar a riqueza da concepção estética da metafísica baumgartiana, em cuja psicologia empírica, aliás, se baseavam os cursos de antropologia. Os dois trabalhos, à espera de merecida publicação, podem ser obtidos no endereço: http://www.teses.usp.br/teses/ disponiveis/. 
A passagem da compreensão mecânica à compreensão finalista do mundo abre uma perspectiva importante para entender a complexa relação entre antropologia e história no interior da filosofia kantiana. Já na Introdução, Kant diz que a antropologia deve anteceder a história, e essa afirmação se torna tanto mais interessante pelo modo como se articula com as três perguntas feitas na Lógica, que aparecem na última seção do Curso. Caberá a essa seção final mostrar que as três questões têm uma localização perfeitamente determinada naquele que será o primeiro momento do aprimoramento do gênero humano, a cultura (Kultur), ao qual sucederão a civilização (Civilisirung) e finalmente a moralização (Moralisirung). Diz o texto:

A cultura se reporta propriamente apenas à pessoa, a civilização se reporta à sociedade; a moralização, ao melhor em geral para o mundo [das allgemeine Weltbeste]. Estes são os três gêneros de progresso, que a natureza implantou nos homens. Já estamos bem adiantados na cultura, na civilização, pouco, e na moralização quase nada fizemos.

No que concerne a cultura, pode-se perguntar:

1) o que posso saber? É o que metafísica e filosofia ensinam.

2) o que posso fazer? É o que a moral ensina.

3) O que posso esperar? É o que a religião ensina.

Os cursos de antropologia têm chamado a atenção dos estudiosos por ser um germinadouro de temas e noções que serão desenvolvidos em diferentes domínios do sistema. Não menos importante que esse aspecto é perceber o quanto Kant enfatiza a importância e novidade da própria disciplina, por ele introduzida pela primeira vez na grade dos estudos filosóficos. Kant tem plena consciência de que é o primeiro a conseguir levar a nova acepção de mundo para dentro da universidade, quando afirma que a antropóloga pragmática não é ensinada em nenhuma outra academia da Europa. A esse respeito, também se pode ler nos cadernos dos alunos do curso de 1784-1785: "Até hoje ninguém apresentou a antropologia dessa maneira, isto é, 
como conhecimento do mundo, e Herr Professor Kant foi o primeiro a fazer um plano para ela e a expô-la em suas aulas".

É claro que, apesar das grandes diferenças de concepção, a antropologia kantiana é, em grande medida, herdeira do projeto que Hume idealizara para a sua ciência da natureza humana: esta só seria implantada, se o mundo erudito ou letrado (learned world) conseguisse chegar ao mundo do convívio social (conversable world), e se os temas ventilados nos salões fossem versados também nas faculdades e conventos. Com o perdão do anacronismo, o que teria pensado Hume se lhe dissessem que a cátedra de filosofia da longínqua universidade de Königsberg adotara o conhecimento da natureza humana como uma de suas matérias, e que o responsável pela disciplina - despertado por ele do sono dogmático - acreditava que aquelas preleções poderiam ser entendidas e lidas até mesmo pelas senhoras da sociedade em seu toucador?

É preciso distinguir duas maneiras de estudar: há ciências elucubrantes, que não são de nenhum proveito para o homem, e noutros tempos houve filósofos, que se chamavam escoláticos, cuja inteira ciência consistia em superar uns aos outros em agudeza; sua arte era ciência para a escola, mas dela não se podia obter esclarecimento para a vida comum. Pode-se ser um grande homem, mas somente para a escola, e sem que o mundo tire proveito de seu conhecimento. A segunda maneira de estudar não consiste apenas em ganhar prestigio junto aos colegas da corporação escolar, mas também em que o saber se estenda além da escola e em que se procure difundir os seus conhecimentos para o proveito geral: é o estudo para o mundo. Escolarmente correta é a ciência que está de acordo com a escola e a retidão profissional; tal perfeição não é de desprezar, pois todas as ciências têm primeiro de ser escolarmente corretas; depois também podem ser acessíveis ao público, a fim de serem aceitas e 
utilizadas por meros amadores. Antes de tudo, a ciência tem de satisfazer aos estudantes do ofício e depois vemos a melhor maneira de ser apreendida pelos homens comuns. Pedante é aquele que faz uso escolástico de seus conhecimentos, sabe designar seus conceitos meramente mediante expressões técnicas e fala somente num palavreado erudito; ele faz uso de meros conhecimentos escolásticos no mundo, mas aqui é preciso saber utilizar seus conhecimentos sempre apenas de maneira acessível ao público, para que também outros nos entendam, e não apenas os doutos de profissão. Provoca riso quando pedantes dão mostras tão inábeis de seus conhecimentos, utilizando-os de maneira escolástica no mundo; pois nada provoca tanto riso quanto alguém que não tem capacidade de discernimento (judicium discretivum) e não vê o que convém às circunstâncias. Por isso, o pedante, que no mais pode ser um homem de mérito, sempre dá ensejo ao riso. É, portanto, necessário que aprendamos a fazer dos conhecimentos que adquirimos nas universidades um uso acessível ao público, para que saibamos, no relacionamento com os homens, como queremos formar homens ou nos fazer estimar entre eles. Temos de lidar, não com a escola, mas com o mundo; temos, pois, de estudar o mundo. Mesmo frequentemente sabendo pouco, um homem tem o traquejo do mundo quando sabe transmitir bem esse pouco a outros homens. Alguém pode ser bastante erudito, mas, como não tem conhecimento do mundo, não pode utilizar isso vantajosamente, nem tirar proveito disso para si e para a comunidade. De resto, conhecimento do mundo significa também conhecimento da natureza, mas esta não é a significação encontrada no linguajar popular, onde significa apenas conhecimento dos homens.

O homem conhece o mundo, isto é, ele conhece o homem em todas as condições. ${ }^{4}$ Conhecimento do mundo, no sentido comum, significa conhecimento dos homens. Os franceses dizem "este ho-

4 Em alemão, Ständen. Num sentido concreto, Stand é o lugar, o posto, a situação em que alguém ou algo se encontra. Mas o sentido aqui é o da situação, condição, estado 
mem tem o traquejo do mundo" ${ }^{5}$ isto é, ele tem conhecimentos que não consistem meramente em especulação, mas conhecimentos que ele pode transmitir ao homem. Precisamos do auxílio de outros homens para alcançar outras coisas; sobretudo por isso, o conhecimento do mundo é chamado conhecimento do homem. Ora, o que é preciso fazer para conhecer o mundo? Para obter conhecimento dele, enquanto um faz viagens, o outro deixa seu circulo familiar e amplia sua esfera de relações até aquela parte da sociedade humana que é a mais cultivada, isto é, até sua parte nobre. ${ }^{6}$ No início, sua esfera de relações se restringia à família, aos camaradas de escola, mas depois ela passa a frequentar as pessoas refinadas. Exercício e experiência são para nós a melhor escola para conhecer os homens, mas eles não bastam por si sós para aperfeiçoar os nossos conhecimentos e torná-los práticos. As relações não ensinam muita coisa se não se aprende a refletir sobre os homens. Por isso, primeiro é preciso conduzir o outro até aquilo a que ele tem de prestar atenção nos homens; é preciso assinalar as idéias fundamentais de onde se pode obter conhecimento dos homens: se não se é instruído a esse respeito, pode-se lidar muito tempo com os homens sem perceber coisa alguma neles. Se, no entanto, alguém nos indicou os principais elementos a que temos de atentar, saberemos aquilo em que temos de reparar. Faz parte, portanto, do conhecimento do homem um ensinamento completo do que é diverso e característico no homem. Esses dois últimos fatores são de grande importância e têm sempre de vir antes no conhecimento

ou status do indivíduo na sociedade. Mais abaixo, Kant dirá que o conhecimento do homem difere de uma condição a outra. (NT)

5 A mesma expressão "Ein Mensch hat die Welt" já foi usada no parágrafo anterior. É uma tentativa de aclimatar em alemão a expressão francesa "avoir du monde", que significa "avoir la pratique de la vie mondaine" ( ter prática na vida mundana ). (NT)

6 Comparar com a Antropologia publicada. Viajar não significa necessariamente conhecer o mundo: Kant adverte que o professor tem geralmente problemas para enxergar as dificuldades dos alunos, pois o salário não o estimula a isso, para o que, de resto, seria preciso já ter conceitos cosmológicos. (p. 895) 
dos homens, e é por meio deles que se tem de ampliar as experiências. Dotados desses ensinamentos, podemos aprender em menos tempo mais do que um outro aprende em sua vida inteira; pois, tendo-os por fundamento, será fácil ampliá-los, e por isso o contentamento com as nossas relações também será maior, porque a maior parte dele reside na reflexão. Quando se erra o tom, com frequência isso pode provocar tédio mortal, mas um indivíduo que pensa sempre encontra matéria para suas observações em tais faltas de sociabilidade; aprende com elas e não passou seu tempo de maneira desagradável. Esses conhecimentos preliminares fornecerão o necessário para prosseguir no conhecimento do homem.

Há três espécies de ensinamento, todas as quais contribuem para nossa perfeição. A primeira nos torna hábeis, a segunda, prudentes, a terceira sábios. ${ }^{7}$ Todas as ciências da escola servirão para a habilidade: é assim, por exemplo, que se aprende história para se tornar hábil em relação às coisas da experiência. Se queremos dar um passo no mundo, temos de aprender como devemos nos tornar prudentes.

O nível mais alto de sabedoria é a perfeição máxima, mas raramente é alcançada. A habilidade é o elemento teórico próprio da escola, mas a instrução que nos torna prudentes é a instrução para a prática, instrução sobre como devemos fazer uso de nossa habilidade. A habilidade está direcionada para coisas, a prudência, para seres humanos. O relojoeiro é hábil, se faz um relógio perfeito; mas se sabe fazê-lo chegar rapidamente ao homem, ao fazê-lo bem segundo a moda, ele é prudente. Contudo, se obtemos alguma influência sobre os homens, temos também uma influência sobre as coisas; pois mãos humanas produzem tudo da rude natureza. A prudência reside, portanto, somente no conhecimento do homem, em virtude do qual estamos em condição de dirigir outros segundo nosso propósito.

7 Em alemão, os adjetivos para hábeis, prudentes e sábios são, respectivamente, geschickt, klug e weise. (NT) 
O conhecimento do homem é de duas espécies: o conhecimento especulativo do homem nos torna hábeis e é tratado na psicologia e na fisiologia, enquanto o conhecimento prático nos torna prudentes; é conhecimento do modo como um homem pode ter influência sobre outro e conduzi-lo segundo o seu propósito. Todo conhecimento prático, quando serve para atingir todos os nossos propósitos, se chama pragmático. Todo ensinamento da sabedoria é moral, e todo ensinamento da prudência é pragmático. Um ensinamento é pragmático, quando nos torna prudentes e úteis em questões públicas, onde não precisamos apenas de teoria, mas também de prática.

O nome geral que usamos para denominar o conhecimento do homem é antropologia, que não é lecionada em nenhuma outra academia. Platner escreveu uma antropologia escolástica. ${ }^{8}$ Nós, porém, não temos outro propósito senão o de extrair regras da diversidade que percebemos no homem; pois, por mais que os humores humanos pareçam ser, indiscutivelmente, diferentes, aqui há, entretanto, mais regularidade do que se poderia pensar. Tentaremos colocar esse jogo das ações humanas sob regras. Todo homem se alegra com uma regra: por exemplo, Sharp, médico inglês, diz em algum lugar que na Inglaterra todos os homens são grossos, à exceção dos estalajadeiros, mas na França todos os homens são finos, à exceção destes últimos. ${ }^{9}$ A causa é: na Inglaterra, há muitos donos de estalagem, e na França, poucos. Essa regra apraz, embora não possa ter fundamento em toda parte.

Em nossa antropologia, não indicaremos, para as regras, outras causas além das que qualquer um pode observar sem perfazer a

8 Ernst Platner, Antropologia para médicos e filosofo, publicada em Leipzig em 1772. (NT)

9 Reinhard Brandt e Werner Stark, editores dos cursos de Antropologia da edição Akademie, indicam que a regra concernente à cordialidade dos estalajadeiros não se encontra nas Letters from Italy, describing the customs and manners of that country, de Samuel Sharp, publicadas em Londres em 1766 e traduzidas para o alemão em 1767. A fonte poderia ser uma carta de Hume a Ramsay de 12 de setembro de 1734. (NT) 
teoria delas. Procuraremos as regras nas diversas experiências que observamos no homem, sem perguntar pelas suas causas. A antropologia escolástica, ao contrário, trata das regras mais universais e de suas causas; portanto, assim que investigamos as causas das regras, caímos na escolástica. Qualquer um poderá ler nossa antropologia, mesmo senhoras em seu toucador, porque proporciona muito entretenimento quando por toda parte a gente depara com regras que indicam saídas, e sempre encontra um fio condutor em meio às aparentes confusões.

Quais são, pois, as fontes da antropologia? O homem não observa os seus móbeis quando estes estão agindo, por exemplo, num estado de afecção ele não pode se observar no jogo de seus móbeis. Mas se ele se observa, todos os móbeis estão em repouso e, por conseguinte, ele não tem nada para observar. Por isso, é difícil observar a mente do homem, assim que seus móbeis estejam atuando. Essa dificuldade, no entanto, diminui quando se começa a observar os outros, porque neste caso se pode ficar bastante tranquilo e aplicar, de tempos em tempos, a si mesmo aquelas observações; pois, estando já de posse de certos conhecimentos, poderemos nos observar mais corretamente de acordo com eles, quando nossa mente estiver em atividade. Relacionar-se com gente de diversas condições e com homens cultivados é fonte bastante fecunda para a antropologia. Entre homens rudes, ainda falta algo para o desenvolvimento de toda a humanidade, porque não tiveram oportunidade de incrementar todas as suas qualidades. Se, no entanto, passo à parte civilizada dos homens, deparo com a dificuldade de que, quanto mais cultivado o homem for, tanto mais quererá se dissimular e tanto menos que um outro o investigue. $\mathrm{O}$ homem da corte não quer se estudado, e a arte do disfarce aumenta quanto maior o cultivo, onde não apenas se dissimula, mas se mostra em si o contrário disso. ${ }^{10}$ Temos, portanto,

10 O texto do manuscrito Petesburg diz não só dissimula [dissimulirt], mas também simula [ simulirt] e o contrário disso". (NT) 
de observar o homem sem nos dar de modo algum o aspecto de observador, tendo também de nos dissimular. ${ }^{11}$ É preciso se portar como se a fala saísse sem nenhuma cautela e ao mesmo tempo prestar bem atenção em tudo o que os outros dizem. Mas é sempre difícil conhecer os homens enquanto se observam suas ações, porque isso exige um observador cultivado e afiado.

Outra fonte da antropologia é a história, mas é preciso que antes exista uma antropologia; pois se não sei a que tenho de prestar atenção, não saberei, unicamente pela narrativa, aquilo que tenho de notar. Romances, comédias, espetáculos teatrais, tragédias, as de Shakespeare, por exemplo, podem proporcionar conhecimentos antropológicos? Espetáculos teatrais e romances sempre exageram aquilo que no mais poderia ser qualidade de um homem. Os autores se baseiam em observações corretas, mas entregam caricaturas, isto é, caracteres exagerados. A antropologia, ao contrário, julgará se os espetáculos teatrais e romances concordam com a natureza humana. Embora poucos, há, por certo, homens que logo sabem colocar em comédia ou tragédia, e de modo apropriado, os conhecimentos que têm do homem. Toda moral exige conhecimento do homem para que não os importunemos com nossas exortações vazias, mas saibamos conduzi-los de tal modo que comecem a ter as leis morais em alta conta, e a fazer delas os seus princípios. Tenho de saber por que vias de acesso posso chegar às maneiras de pensar e sentir dos homens, a fim de produzir decisões; para nós, o conhecimento do homem pode dar ensejo a que o educador, o pregador, não seja capaz de provocar apenas soluços e lágrimas,

11 Como observará o curso, a recomendação de que se aja como um ator em sociedade não é um elogio ao cinismo (Menschenkunde, p. 930-31). A argumentação é pontual e tem inspiração rousseauniana: lidar com homens simples não requer fingimento, mas quando julga a alta sociedade, o antropólogo se encontra numa posição muito desfavorável, pois os nobres estão muito próximos uns dos outros, mas bem distantes dos demais (KANT, Antropologia de um ponto de vista pragmático. Tradução de Clélia Aparecida Martins. São Paulo: Iluminuras, 2006, p. 22) 
mas verdadeiras decisões. Ele é igualmente indispensável na política; pois, para poder governar homens, é preciso conhecê-los; sem conhecimento deles, o governante não poderá dirigir gente de tantas condições, tudo lhe resistirá, e ele não poderá conduzi-los segundo sua vontade.

O relacionamento é uma das grandes utilidades da antropologia, já que nos torna aptos para ele e também fornece belo material para entretenimento; pois muitas matérias não são para a sociedade; uma jovem não pergunta pelos assuntos de Estado, mas quer ser entretida, e então se descobre que certas observações sobre o ser humano agradam, porque todo homem pode fazê-las a respeito de si mesmo. Portanto, já que esse estudo é tão atraente e tão importante para cada um, é justo que seja tido em alta conta. Muitos escritores afirmam que é difícil conhecer a si mesmo. Se devo me conhecer pela comparação com outros, e se a questão é se me conheço melhor do que outros, é manifesto que cada homem é quem tem de poder conhecer melhor a si mesmo; pois, como é ele quem pode procurar o fundamento de todos os seus pensamentos e móbeis, e como não pode haver dissimulação ou disfarce com respeito a si mesmo ou ao conhecimento de si próprio, não sei a quem posso conhecer melhor do que a mim mesmo. Mas se afirmação equivale a dizer: "conheça o homem em geral", então certamente o conhecimento do homem é difícil, pois se quero conhecê-lo, não posso compará-lo com nenhuma outra coisa; se devo conhecer a mim mesmo, posso me comparar a outros e, portanto, conhecer com mais precisão, por aquilo que tenho de diferente de outros. Mas se pergunto O que é o homem?, não posso compará-lo com os animais, porque tem a vantagem de não ser um. O conhecimento do homem em geral é, portanto, difícil, o conhecimento particular de um homem já é mais fácil, e o mais fácil é o autoconhecimento, pois não posso dissimular diante de mim mesmo e, por conseguinte, aqui caem todos os velamentos com que os outros homens se cobrem. 
Como não há outro livro sobre antropologia, escolhemos como fio condutor a psicologia metafísica de Baumgarten, homem bastante abundante na matéria e bastante sucinto na apresentação. 